УДК 323+328.1:001.18:004.413.4

\author{
Войтко С. В. \\ доктор економ. наук, професор
}

Цимбаленко Я. Ю.,

канд. наук з держ. управління, доцент

Національний технічний університет України "КПI"

\title{
ІНДЕКСИ ПОЛІТИЧНОЇ СТАБІЛЬНОСТІ ТА ЕФЕКТИВНОСТІ РОБОТИ УРЯДУ У ПЕРЕДБАЧЕННІ ЗАГРОЗ КРАЇНІ
}

\section{ИНДЕКСЫ ПОЛИТИЧЕСКОЙ СТАБИЛЬНОСТИ И ЭФФЕКТИВНОСТИ РАБОТЫ ПРАВИТЕЛЬСТВА В ПРЕДВИДЕНИИ УГРОЗ СТРАНЕ}

\section{INDICES OF POLITICAL STABILITY AND GOVERNMENT EFFECTIVENESS IN PREDICTING POSSIBLE THREATS TO THE COUNTRY}

Визначено актуальність дослідження геополітичних викликів сьогодення. Здійснено вибірку даних для аналізу, у яку увійшли наукові доробки The Worldwide Governance Indicators (WGI). Сформовано базу порівняння на основі індексу політичної стабільності, індексу ефективності роботи уряду та індексу якості регулювання. Окреслено гіпотезу про те, щзо політична стабільність у країні залежить від якості регулювання та ефективності роботи уряду. Запропонована та апробована методика дослідження місия положення країн у координатах обраних індексів. Визначено можливі причини політичної нестабільності. Розраховано числові значення кореляційного зв'язку для індексів. Візуалізовано розміщення країн у двомірному просторі для індексу політичної стабільності та індексу якості регулювання. Визначено краӥни-сусіди для України у просторі визначених індексів. Доведено, щзо запропонований методичний підхід надає змогу об'єктивно очінити стан дестабілізуючих політичних прочесів на можливі збройні конфлікти.

Ключові слова: політична стабільність, ефективність роботи уряду, якості державного регулювання.

Определены актуальность исследования геополитических вызовов современности. Осуществлен выборку данных для анализа в которую вошли научные труды The Worldwide Governance Indicators (WGI). Сформирована база сравнения на основе индекса политической стабильности, индекса эффективности работы правительства и индекса качества регулирования. Определень гипотезу о том, что политическая стабильность в стране зависит от качества регулирования и эффективности работь правительства. Предложена и апробирована методика исследования места положения стран в координатах избранных индексов. Определены возможные причины политической нестабильности. Рассчитано числовые значения корреляционной связи для индексов. Визуализировань размещения стран в двухмерном пространстве для индекса политической стабильности и индекса качества регулирования. Определены странысоседи для Украины в пространстве определенных индексов. Доказано, что предложенный методический подход дает возможность объективно оценить состояние дестабилизирующих политических процессов на возможные вооруженные конфликты. 
Ключевые слова: политическая стабильность, эффективность работы правительства, качества государственного регулирования.

In the research, the selection of data for analysis includes scientific portfolio of The Worldwide Governance Indicators (WGI). The comparison base has been formed based on Political Stability Index, Government Effectiveness Index and Regulation Quality Index. We outline the hypothesis that the political stability in a country depends on the quality of regulation and effectiveness of the government. Hence, the methodology of investigating into the country's position within the coordinates of the indexes chosen is applied. After possible reasons for political instability had been outlined and the numerical values calculated, we visualized the position of country in the two-dimensional plane of indices of political stability and government effectiveness. The neighboring countries for Ukraine in the two-dimensional plane were defined. As a result, it has been proved, that the suggested methodological approach enables to objectively evaluate the impact of destabilizing political processes over possible military conflicts.

Keywords: political stability, government effectiveness, regulatory quality.

Вступ. На сьогодні досить актуальним залишається питання стосовно виникнення причин і можливих наслідків зміни світового порядку у 2014-2015 роках. Спільними зусиллями провідні країни світу, ще починаючи з 1945 року, визначили принципи, формували та підтримували правила функціонування країн. Проте геополітичні виклики окремих країн зумовили зростання рівня напруженості на Євразійському континенті, а також зумовили певну дестабілізацію у світовій економіці. Зазначене ще більш відчутне у зв'язку 3 післядією ефектів глобальної економічної кризи, що розпочалася у 2008 році. Низка зовнішніх і внутрішніх факторів у комплексі зумовили таку складну політичну ситуацію. Особливого значення процес переділу усталених кордонів має саме для України.

Поточна ситуація $є$ наслідком низки подій, особливу роль у яких відігравали управлінські рішення окремих осіб. Звичайно, ці рішення були зумовлені значною кількістю зовнішніх факторів. Проте саме ці фактори зумовили ті обставини, що зіграли вирішальну роль. У будь-якому випадку вплив носить комплексний характер, а визначення ретроспективи, поточного стану та перспектив розвитку можливо визначити, використовуючи інтегральні індекси, які більшою мірою відображають ті складові, що відповідають поставленим задачам.

Авторами обрано для дослідження реалізований проект, результати якого приведено в [1]. У цьому дослідженні розглянуто як одиночні, так і інтегральні показники державного управління для 215 країн за період 31996 по 2013 рік. Саме The Worldwide Governance Indicators (WGI) агрегує показники ефективності державного управління за такими 6 вимірами: 1) Голосування та підзвітність (Voice and Accountability); Політична стабільність і відсутність насильства / тероризму (Political Stability and Absence of Violence / Terrorism, далі у тексті зазначатиметься «Політична стабільність»); Ефективність роботи уряду (Government Effectiveness); Якість 
регулювання (Regulatory Quality); Верховенство права (Rule of Law); Боротьба 3 корупцією (Control of Corruption). Зазначені інтегральні показники формуються експертною та математичною обробкою 31 базових джерел даних. Детальна інформація, що лежать в основі джерел даних, методи агрегації та інтерпретації показників приведено в роботі [2, с. 3-5].

Подібні розробки здійснюються низкою авторитетних організацій. Ці розробки стосувалися як економічних, так і соціальних вимірів. Заслуговують на увагу наукові доробки The Heritage Foundation [3] та World Economic Forum [4], якими за власними методиками розраховували індекси «Index of Economic Freedom» та «Global Competitiveness Index». Інтегрування зазначених індексів здійснюється у Світовому центрі даних з геоінформатики та сталого розвитку та представлено на сайті [5]. Досить містка база даних для різнобічного аналізу знаходиться на сайті Світового банку (World Bank) [6], де представлено інформацію про понад 5 тисяч показників за усіма країнами світу. Подібний до цього аналіз проводився авторами на основі розрахунків Індексу державної неспроможності (Failed States Index), що надається організацією Foreign Policy проводиться на сайті [7].

Постановка завдання. Стабільне функціонування світової спільноти передбачає взаємодію господарських механізмів усіх суб'єктів. Важливими складовими цих механізмів $\epsilon$ політична стабільність та, відповідно, ефективність роботи уряду як в окремій країні, так і у світі в цілому. Порушення балансу приводить до негативних, а в окремих випадках $\mathrm{i}$ до катастрофічних наслідків. Так, на сьогодні у різних фазах знаходяться близько півтора десятки конфліктів, у яких загинуло понад 1 тисячу осіб (з 2009 року за даними Центру оборонної інформації (Center of Defense Information) [8]). 3а останнє десятиліття слід відмітити окремі конфлікти, що відбувалися в Грузії (Абхазія та Південна Осетія), Іраку, Ізраїлі, Афганістані, Індії (Кашмір), ШріЛанці, Колумбії, Конго, Нігерії, Сомалі, Судані, Уганді, Сирії, Лівані, Україні (Крим, Донбас). Саме тому виникає потреба у дослідженні, яке носить комплексний характер і надає можливість узагальнити місце та роль тієї чи іншої країни у стабільності мирного співіснування світової спільноти. Військова агресія може бути породжена низкою обставин.

Нами висувається гіпотеза про те, що політична стабільність у країні залежить від якості регулювання та ефективності роботи уряду. Постає завдання розроблення та апробації методики, яка надає змогу, використовуючи окремі індикатори, що запропоновані в [1], здійснити аналіз місця положення країн у координатах політичної стабільності, ефективність роботи уряду та якості державного регулювання. Це сприятиме об’єктивному оцінюванню причин та наслідків дестабілізуючих процесів 3 можливістю військових конфліктів. 
Науковою проблемою є об'єктивне оцінювання політичної ситуації у державі на основі інтегральних показників, які розроблені авторитетною організацією, та експертна оцінка причин зростання рівня політичної нестабільності у державах.

Основними завданнями статті $є$ визначення можливих причин політичної нестабільності шляхом порівняння значень індексів, що досліджуються для України зі значенням тих же індексів для інших країн. Також ставиться завдання виявлення характерних особливостей у взаємному розміщенню країн у системі координат індексу політичної стабільності, індексу ефективності роботи уряду та індексу якості регулювання.

Методологія. Теоретичну основу дослідження складає комплексний підхід до аналізу співвідношення індексів, що характеризують державу як об'єкт у зрізах політичної стабільності, ефективності роботи уряду та якості державного регулювання.

Базою для дослідження $є$ запозичені дані 3 [1]: індекс політичної стабільності (Political Stability and Absence of Violence/Terrorism); індекс ефективності роботи уряду (Government Effectiveness); індекс якості регулювання (Regulatory Quality).

Методологічною основою наукового дослідження обрано методи комплексного аналізу інтегральних показників, використано елементи компаративного, кореляційного аналізу та логічного узагальнення.

Результати дослідження. На основі аналізу отриманих даних за 2013 рік (дослідження проводилося у 2014 році на основі аналізу показників 215 країн) авторами сформовані таблиці, на основі яких здійснювалося дослідження. Результати аналізу кореляційного зв'язку приведені у табл. 1.

Таблиця 1

\section{Матриця значень кореляційного зв'язку між індексами політичної стабільності, ефективності роботи уряду та якості регулювання}

\begin{tabular}{|l|c|c|c|}
\hline \multicolumn{1}{|c|}{ Назва індексу } & $\begin{array}{c}\text { Regulatory } \\
\text { Quality }\end{array}$ & $\begin{array}{c}\text { Political } \\
\text { Stability }\end{array}$ & $\begin{array}{c}\text { Government } \\
\text { Effectiveness }\end{array}$ \\
\hline Regulatory Quality & 1,000 & 0,618 & 0,930 \\
\hline Political Stability & 0,618 & 1,000 & 0,706 \\
\hline Government Effectiveness & 0,930 & 0,706 & 1,000 \\
\hline
\end{tabular}

Кореляційний аналіз показав те, що між усіма індексами має місце суттєвий зв'язок. Найбільше значення кореляційного зв'язку спостерігається між індексом ефективності роботи уряду (Government Effectiveness) та індексом якості регулювання (Regulatory Quality). Найменше значення 
кореляції між індексом політичної стабільності та індексом якості регулювання. Візуалізація для менш пов'язаних індексів (індекс політичної стабільності, індекс якості регулювання) приведена на рис. 1. Для більш глибокого аналізу розміром кола показано значення індексу ефективності роботи уряду.

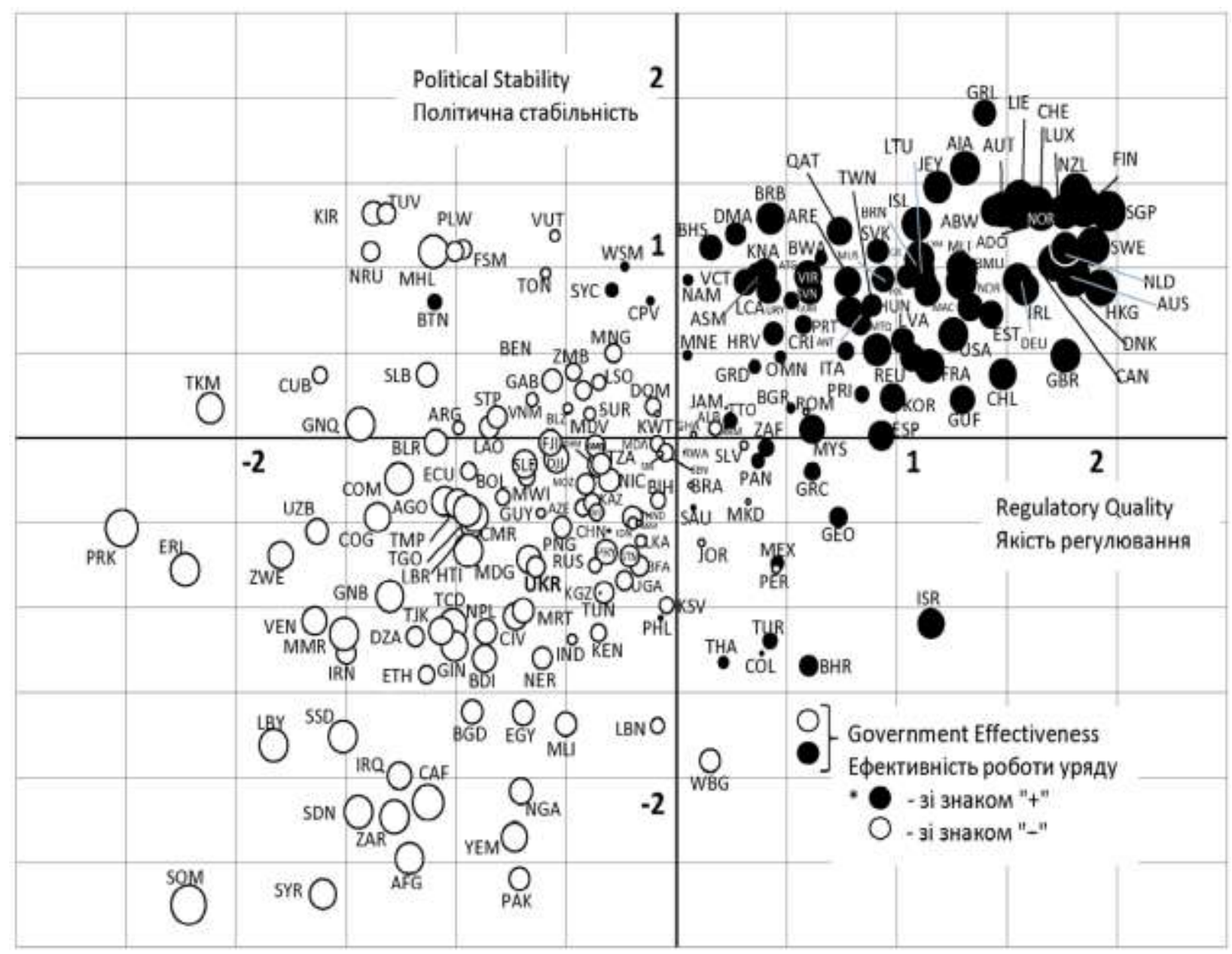

Рис. 1. Співвідношення країн у координатах індексу політичної стабільності та індексу якості регулювання (довідково площею кола приведено індекс ефективності роботи уряду)

Отже, Україна у 2013 році мала всі значення індексів зі знаком «мінус» у проміжку обчислення цих індексів в інтервалі від $-2,5$ до $+2,5$. Маючи такі значення доцільно розглянути країни-сусіди за значеннями цих індексів (табл. 2). Ця таблиця сформована таким чином, що у ній представлено 10 країн, що мають дещо вищі та 10 країн, які мають дещо нижчі значення відповідних індексів. Для України приведено відносне значення «0», а у дужках показано абсолютне місце серед 215 країн. Назви країн приведені за стандартом Alpha3 (трьохбуквений код за ISO 3166-1). 
Таблиця 2

Числові значення індексів політичної стабільності, ефективності роботи уряду та якості регулювання для окремих країн

\begin{tabular}{|c|c|c|c|c|c|c|}
\hline ' & Code & 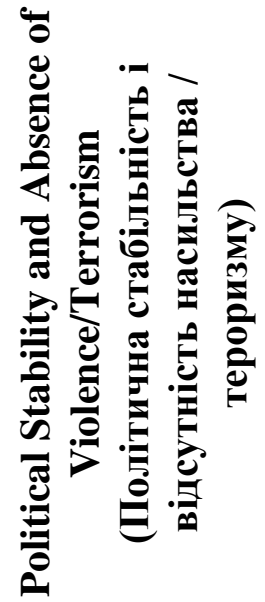 & Code & 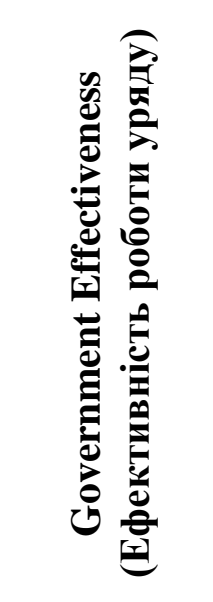 & Code & 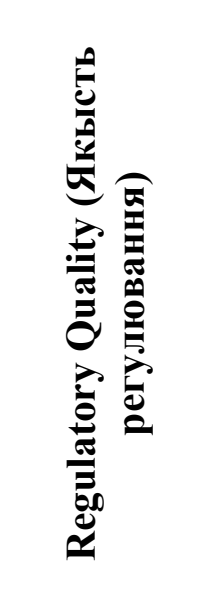 \\
\hline 10 & LKA & $-0,61$ & MNG & $-0,54$ & BLZ & $-0,49$ \\
\hline 9 & JOR & $-0,62$ & BEN & $-0,55$ & MLI & $-0,50$ \\
\hline 8 & HTI & $-0,66$ & FSM & $-0,56$ & PNG & $-0,52$ \\
\hline 7 & PRY & $-0,67$ & MWI & $-0,56$ & DJI & $-0,55$ \\
\hline 6 & ZWE & $-0,69$ & UGA & $-0,58$ & VUT & $-0,55$ \\
\hline 5 & GTM & $-0,69$ & NRU & $-0,59$ & GAB & $-0,56$ \\
\hline 4 & MDG & $-0,71$ & PLW & $-0,59$ & FJI & $-0,57$ \\
\hline 3 & MEX & $-0,74$ & DZA & $-0,60$ & TON & $-0,59$ \\
\hline 2 & RUS & $-0,75$ & BFA & $-0,62$ & NER & $-0,61$ \\
\hline 1 & BFA & $-0,75$ & MOZ & $-0,65$ & GUY & $-0,62$ \\
\hline $\mathbf{0}$ & UKR & $-0,76(167)$ & UKR & $-0,65(147)$ & UKR & $-0,64(156)$ \\
\hline-1 & PER & $-0,77$ & TUV & $-0,65$ & VNM & $-0,65$ \\
\hline-2 & ERI & $-0,78$ & TZA & $-0,67$ & $\mathrm{MDG}$ & $-0,67$ \\
\hline-3 & UGA & $-0,84$ & KGZ & $-0,69$ & MWI & $-0,68$ \\
\hline-4 & KGZ & $-0,91$ & IRN & $-0,70$ & SLE & $-0,69$ \\
\hline-5 & TUN & $-0,91$ & NER & $-0,71$ & EGY & $-0,70$ \\
\hline-6 & GNB & $-0,93$ & GTM & $-0,71$ & MRT & $-0,70$ \\
\hline-7 & KSV & $-0,98$ & PNG & $-0,71$ & NGA & $-0,71$ \\
\hline-8 & MRT & $-1,02$ & GMB & $-0,72$ & PAK & $-0,71$ \\
\hline-9 & CIV & $-1,05$ & STP & $-0,74$ & CIV & $-0,73$ \\
\hline-10 & PHL & $-1,06$ & HND & $-0,74$ & YEM & $-0,74$ \\
\hline
\end{tabular}

Варто звернути увагу, що саме на 2013 рік маємо ситуацію, у якій один індекс (Політична стабільність і відсутність насильства / тероризму) для України та Російської Федерації має практично однакові значення. Для детального дослідження пропонується розглянути країни, що знаходяться безпосередньо біля України (на рис. 2 візуалізовано 80 країн у системі координат індексу політичної стабільності та індексу якості регулювання. 


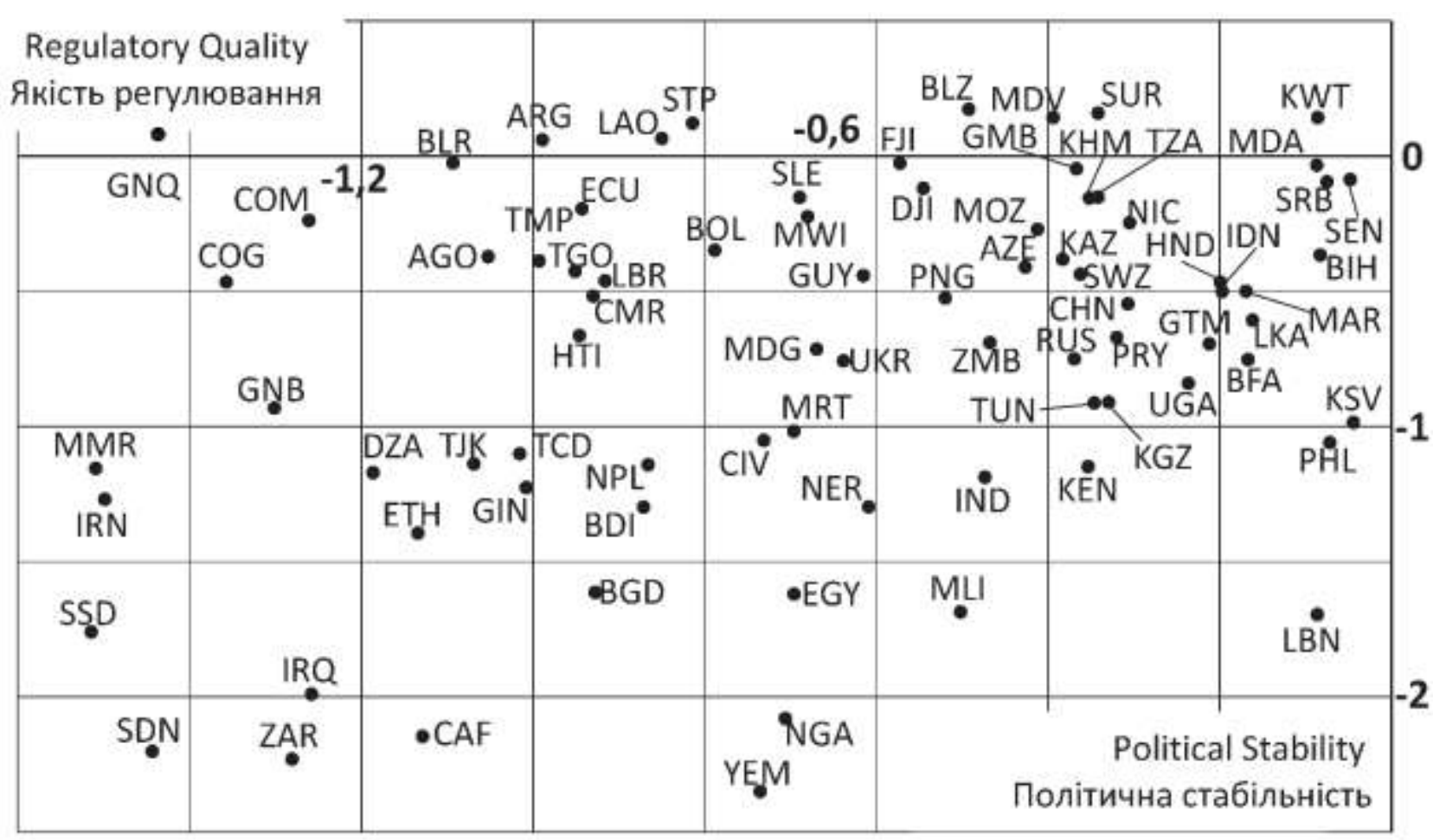

Рис. 2. Співвідношення окремих країн у координатах індексу політичної стабільності та індексу якості регулювання

Аналіз місця розташування України показує, що з країн-сусідів поряд знаходиться лише РФ, яка використала ситуацію у своїх корисних цілях, маючи подібний політичний стан у власній країні.

Висновки. На підставі проведеного аналізу з використанням значень індексу політичної стабільності (Political Stability and Absence of Violence/Terrorism), індексу ефективності роботи уряду (Government Effectiveness) та індексу якості регулювання (Regulatory Quality) визначено можливі причини порушення світового порядку після Другої світової війни, а саме низькі значення країн-сусідів за індексом політичної стабільності, вірніше високе значення політичної нестабільності. Також суттєвим показником виявилася якість державного регулювання. Висунута гіпотеза доведена, результати дослідження мають практичне значення, яке полягає у прогнозуванні стану політичної напруженості для країн-сусідів.

Таким чином запропонований методичний підхід надав змогу, використовуючи окремі індикатори, що стосуються політичної стабільності, регуляторної політики та ефективності роботи уряду, об'єктивно оцінити стан дестабілізуючих процесів, що, на відміну від існуючих підходів, базується на основі інтегральних показників 3 можливістю визначення причин політичної нестабільності шляхом порівняння значень індексів. Базою для дослідження слугували дані з [1], а саме індекс політичної стабільності (Political Stability 
and Absence of Violence/Terrorism), індекс ефективності роботи уряду (Government Effectiveness) та індекс якості регулювання (Regulatory Quality). Подальші наукові дослідження можливі у визначенні динамічних характеристик вищезазначених індексів 3 метою прогнозування дестабілізуючих процесів між країнами-сусідами.

\section{Лiтература:}

1. The Worldwide Governance Indicators (WGI) project [Electronic Resource] The World Bank Group, 2014. - Mode of access : http://info.worldbank.org/governance/wgi/index.aspx\#home

2. Kaufmann D. The Worldwide Governance Indicators: Methodology and Analytical Issues / D. Kaufmann, A. Kraay, M. Mastruzzi // World Bank Policy Research Working Paper, September, 2010. - No. 5430. - $31 \mathrm{p}$.

3. Офіційний сайт HF [Electronic Resource] : Heritage Fundation. - Електрон. дан. , 2015. Mode of access : www.heritage.org

4. Офіційний сайт WEF [Electronic Resource] : World Ecomomic Forum. - Електрон. дан., 2015. - Mode of access : www.weforum.org.

5. База даних Світового центру даних з геоінформатики та сталого розвитку [Електронний pecypc]. - Режим доступу : http://wdc.org.ua/uk/data

6. Офіційний сайт The World Bank. Data \& Research. [Electronic Resource] - Mode of access : http://data.worldbank.org/

7. Foreign Policy: Рейтинг несостоятельности государств мира (Failed States Index) — 2013 [Electronic Resource] - Mode of access : http://www.foreignpolicy.com/

8. Center for Defence Information [Electronic Resource] - Mode of access : http://www.crin.org/en/library/organisations/center-defence-information 